\title{
MIT agrees to accept Whitehead grant
}

\section{Faculty votes}

\section{yes, but some}

\section{strings remain}

\section{Washington}

Despite strong objections from several members of its science departments, the full faculty of Massachusetts Institute of Technology (MIT) voted by an eight-toone margin last week to approve MIT's acceptance of an offer from multimillionaire Edwin (Jack) Whitehead to set up an independent biomedical research centre associated with the institute.

The faculty's approval gives'a green light to the MIT Corporation and the institute's president, Dr Paul E. Gray, to accept $\mathrm{Mr}$ Whitehead's offer of an initial \$20 million for the capital costs involved in building the research centre, and an eventual endowment of $\$ 100$ million to cover operating costs. The centre's main goal will be to pursue research into the applications of molecular genetics to developmental biology.

The money will allow the centre, which will be headed by Nobel laureate and MIT biology professor David Baltimore, to recruit at least 20 full-time professors. All will be members of MIT's biology department, since although funding for the centre will be controlled by members of $\mathrm{Mr}$ Whitehead's immediate family and other trustees nominated by him, the centre will for academic purposes be treated as an integral part of MIT.

When details of Mr Whitehead's original offer became known early in the summer, several faculty members complained that research staff at the centre would be subject to a "dual allegiance" that could lead to tensions between them and other MIT academics (Nature 1 October, p.329). Concern was also expressed at the original proposal made by $\mathrm{Mr}$ Whitehead - cofounder and president of the laboratory instrument company Technicon, which was bought by Revlon in August 1980 in a deal that involved the transfer of $\$ 300$ million in Revlon stock to him - that the research centre should own all the patents originating from its work and benefit directly from their licensing.

In the intervening period, the terms of the proposed arrangement have been modified to give MIT more direct control of the centre. Thus all new faculty members appointed to the centre will be required to adhere to existing MIT rules on salaries and benefits, and fulfil the conventional teaching and committee responsibilities of other MIT academics.

Mr Whitehead has insisted, however, that the funds for the centre, to be known as the Whitehead Institute for Biomedical Research, remain under the control of its finance committee and that his three children should remain a majority on the committee. The conventional arrangement is for a benefactor to provide funds directly to a university, but he says that if he had wanted to give the money to MIT and let the institute decide how to spend it, he would have done so.

Not all the critics have been satisfied with the concessions that $\mathrm{Mr}$ Whitehead has agreed to. In a letter circulated before last week's meeting, 33 faculty members expressed their continuing "deep concern" about the implications of the proposed arrangements. The lettcr, drawn up by physics professor Anthony French and biology professor John Buchana complained that the centre's staff would be selected primarily for their potential contribution to its research activities rather than in order to meet MIT's educational needs; that the creation of the centre would lead to an imbalance in the biology department, since it would provide onethird of the full professors; and that there would be a lack of symmetry between the voting power of the centre's scientists over the work of the rest of the biology department and vice versa.

MIT officials, however, are keen to accept $\mathrm{Mr}$ Whitehead's offer, which they see as helping to keep MIT in the forefront of biological research and its potential

\section{Mitterrand embraces information policy}

M. Francois Mitterrand, President of France, is wasting no time responding to the "information shock" - the complex of issues surrounding microelectronics and unemployment.

In June, Mitterrand asked the publisher Jean-Jacques Servan-Schreiber (who had written a book on the subject) to gather a few experts to study the question. ServanSchreiber's response came last week in a report which proposed the setting up of a world centre in Paris. This would gather together international experts in informatics, and have a budget of around $£ 10$ million a year ( $£ 4$ million of which would pay the 60 staff). Within the week, Mitterrand had agreed and ordered that the details should be worked out within a fortnight. So the World Centre on Informatics should be in action in 1982 .

What it will do, however, is not clear. Servan-Schreiber's vision is of a transformation of the world mediated by the development of the personal computer (something cheaper and more accessible than the present office and household machines). Such computers could make work more varied and creative, and provide everyone - including the Third World - with almost unlimited access to information. Development is a matter of commercial application. In a letter circulated to all faculty members before last week's meeting, Dr Gray and MIT provost Francis Low said they shared the general concern about the potential problems that could arise as a result of the dual loyalty of faculty members. But they added: "Although this risk cannot be eliminated, in our view the worries are based on worst-case scenarios that are not likely to materialize"'

After a sometimes stormy debate, in which Dr Gray said he did not know the detailed reasons why a similar offer from Mr Whitehead had been turned down by faculty members of Duke University in North Carolina in 1974, a motion to support the creation of the research centre was approved on a straw vote by a majority estimated as eight-to-one. At the same time, the motion said that members of the faculty "acknowledge the existence of legitimate, deep concern over the risks inherent in the venture, and hope that efforts to minimize these risks will continue".

$\mathrm{Mr}$ Whitehead's offer will now be formally considered by the members of the corporation, the controlling body of MIT, when they meet on 4 December, and is expected to be accepted. Dr Baltimore expects the new institute to get under way as soon as the affiliation had been formally approved by the corporation.

David Dickson

education, he says, and the personal computer can facilitate it. The world centre, therefore, should observe and assist this transformation.

Mitterrand, however, is aware that in industry the application of microelectronics might cause unemployment, and that the computer can interfere with liberty and privacy. At the same time, he considers that the economic development of France, and of other Western nations may depend on the rapid implementation of microelectronics and informatics. Elected to conquer unemployment, and determined to increase his country's economic strength, he needs an answer to this dilemma and hopes that the world centre, as a kind of full-time standing committee of academics, will provide it.

Although the precise form of the centre has yet to be determined, the staff is certain to be international. So far, ten experts have expressed interest in joining - seven from America, two from Scandinavia and one from China.

If the centre develops as Mitterrand wishes, it will:

- Monitor the applications and effects of microelectronics worldwide.

- Forecast the possible role of France in these developments. 
- Study how to educate users and potential users of microelectronics, particularly in relation to maintaining employment.

- Help develop new programs and languages appropriate to a personal computer (Servan-Schreiber version).

- Propose the means of transferring the technology to the Third World.

Robert Walgate

\section{Magnetospheric experiment UK joins in}

The Science and Engineering Research Council has decided to fund participation by the United Kingdom, to the tune of $£ 2$ million, in the Active Magnetospheric Particle Tracer Explorers project (AMPTE). The council's Rutherford Appleton Laboratory, in partnership with the Mullard Space Science Laboratory of University College London and other university groups, will be developing the satellite as a separate component of the Ion Release Module satellite being developed by the Max Planck Institutes of

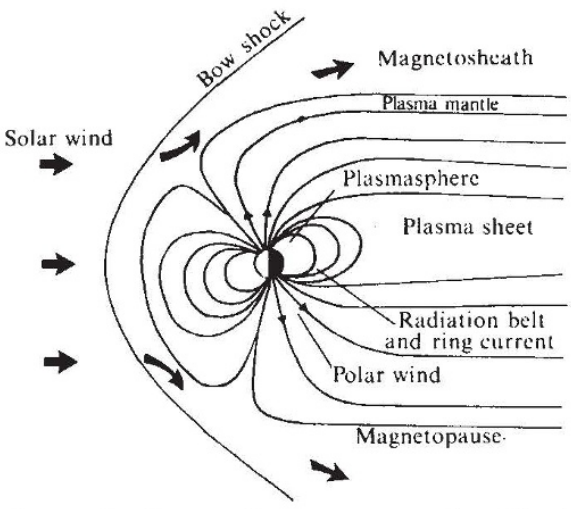

Astrophysics and Aeronomy in West Germany. The two satellites, together with the Charge Composition Explorer satellite being developed in the United States, will all be launched in mid-1984 on a Thor Delta rocket, hastily acquired following space shuttle delays.

The magnetosphere is the region where the magnetic field of the Earth interacts with the charged particles and magnetic fields of the solar wind, the continuous flow of plasma from the Sun. The aims of the experiment are to release lithium and barium ions into the Earth's magnetosphere and, by monitoring their subsequent behaviour, to investigate several fundamental aspects of the magnetosphere as well as to simulate conditions near other planets. The Ion Release Module will be placed in a highly eccentric orbit, so that ions may be released both inside and outside the magnetosphere.

One of the problems to be tackled by the Charge Composition Explorer is to determine whether or not the magnetosphere is "open" - that is, whether the Earth's magnetic field lines can connect with those of the interplanetary medium so that solar plasma can enter the Earth's field from downwind. To this end, ions will be released just upstream of the bow-shock. The Charge Composition Explorer, in an equatorial orbit, will detect those ions only if the magnetosphere is "open".

The UK satellite will be placed in an orbit with that of the release module, maintaining a separation of $100 \mathrm{~km}$ or so. The particle and field detectors on board will monitor the behaviour of the ejected ions immediately after release. Lithium ions, being light, should pick up a large component of the velocity of the solar wind unless disturbed by plasma instabilities.

The release of the barium ions should produce rather more spectacular results. Because they are more massive than most components of the solar wind, the surrounding plasma will be impeded and a glowing comet-like structure will be produced. If the barium ions are released within the high-velocity plasma of the magnetosheath near dawn or dusk, the cloud will be visible from the ground, and will simulate conditions to be found in comets and in the magnetosphere of Venus. When released "downwind" in the magnetotail, where plasma flows more slowly, conditions will be more similar to those near Io and Titan within the magnetospheres of their respective planets Jupiter and Saturn.

Philip Campbell

\section{NASA budget Small is necessary}

\section{Washington}

As the National Aeronautics and Space Administration (NASA) locks horns with the Reagan Administration over just how large a budget cut it must face next year, US space scientists are trying to devise a strategy for exploring the Solar System within the tight budget constraints likely to dominate for the next few years.

For the fiscal year beginning 1 October 1982, the Office of Management and Budget (OMB) has told NASA to prepare for cuts of about $\$ 1,000$ million in a budget previously projected at about $\$ 7,000$ million. Agency officials are strongly resisting this request, arguing that such a cut would severely damage all NASA's programmes; they have already gone over OMB's head to the White House in an attempt to get the proposed cuts reduced before the budget is formally submitted to Congress in January.

However, the prospects for NASA in general - and space science in particular - are likely to be bleak for the next few years. In this context, the agency has set up a Solar System Exploration Committee to take a close look at the type of projects it should be planning for the future. "If something disastrous were to occur to NASA's budget next year, it would be even more important to plan how we should recover", Dr Noel Hinners, the committee's chairman and director of the National Air and Space Museum in
Washington said last week.

The main aim of the committee is to increase the efficiency of planetary and other Solar System missions while reducing the costs, in particular by breaking down the scientific goals of the missions into "smaller bites" than those represented by, for example, Voyager.

One way of achieving this goal would be to build directly on the experience of previous missions. For example, the Ames Research Laboratory is looking at ways of developing Picneer-type orbiters to some of the inner planets, using derivatives of terrestrial orbiters to study the geological characteristics of the Moon or Mars.

Pioneer-type spacecraft would only be able to achieve relatively limited scientific objectives, and would produce a relatively low data rate. But a mission could be launched for between $\$ 100$ and $\$ 150$ million, the same order of magnitude as the Explorer satellites currently being successfully used by NASA.

As well as looking at ways of using smaller spacecraft, the committee is investigating how to save money by increasing operations efficiency, for example by reducing the length of trips, compressing the scientific data to be transmitted back to Earth or the sharing of individual pieces of equipment between different research groups.

Four subcommittees will meet next month at the Jet Propulsion Laboratory to work out the type of programme that could be developed on the basis of such components. The subcommittees expect to report to NASA with specific mission proposals by next summer.

Dr Hinners said last week that he had discussed this new approach in some detail with officials at OMB, who expressed general approval but raised two possible objections. First that a list of the various missions which could be included in an overall envelope of between $\$ 300$ and $\$ 400$ million a year - only slightly above the current level - looked like an ambitious shopping list; and second, that breaking down planetary missions into smaller projects might lack the public appeal of Apollo or Voyager.

To the first objection, NASA replies that it is the size of the effort and the balance between costs and return that should be measured rather than the number of space vehicles flown. The second objection raises a broader question faced by NASA: can the apparently-increasing enthusiasm among the public for space exploration, particularly in the light of the excitement generated by photographs sent back by the Voyager spacecraft, be interpreted as a mandate to increase spending on space science?

Those who do believe that the public will be eager to support ambitious plans for space exploration are still pushing hard for what they consider should be the next major mission, a manned sample-return space vehicle to Mars. NASA administrator James Beggs told the advisory 